aortic valves. There was some perisplenitis, a few pleural adhesions, hæmorrhagic spots on the knees, and altered blood in the intestines. It would appear probable that the cause of death was the hæmorrhage into the bowel which must have taken place. The growth into the stomach was ulcerated, but there was no direct evidence that the blood, which was not in large amount, came from there. The bone marrow was examined in smears, but no cancer eells were found. There were a few white areas in the marrow seen with the naked eye, but these were due to

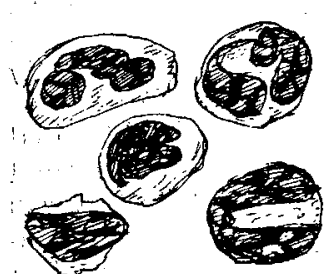
localised leucoblastic reaction. Only the marrow of the sternum was examined, a small piece being trephined for the purpose.

There is thus no direct evidence of bone metastases in this case. The evidence for their existence is the difficulty of explaining the blood picture otherwise. It may well be Sketch of small "giant argued that this evidence is very cells" from the blood slight; that is admitted, but however in Case 4.

that may be, the resemblance to other cases makes this one worthy of record. There was one rather remarkable point about this case, and that was the presence in the blood of many cells between $20 \mu$ and $30 \mu$ in diameter and apparently identical with the smaller giant cells seen in the marrow films after death. Except for the few megaloblasts and the very large number of normoblasts, the marrow was very like that of Addisonian anæmia. The one blood examination is subjoined.

In the first three cases there was obvious involvement of the marrow in metastases from primary cancerous growths. In all of these the blood picture was distinctly abnormal and similar in type, although in the first case the more marked abnormalities were of late occurrence only. The last case resembles very closely the case of Harrington and Kennedy, but there were no metastases in the small area of marrow examined. Until more cases have been collected useful comment is almost impossible, and these cases are therefore left without it. They may be of interest to those who, like myself, are keeping an eye on the literature of the subject and endeavouring to find fresh cases.

West Kensington.

\section{FATAL HAMATEMESIS IN A CASE OF HEPATIC SYPHILIS.}

BY DONALD E. CORE, M.D. VICT., M.R.C.P. LOND., PHYSICIAN, ANCOATS HOSPITAI, MANCHESTER.

THE patient, a young man, aged 29, a labourer, quite suddenly while at work vomited a large quantity of blood. He was taken to the central receiving house of the Manchester Royal Infirmary, and while he was there he again vomited blood. He was sent to the infirmary at once, and when he arrived there he was found to have had another and very severe hæmatemesis in the ambulance. He was in a state of extreme collapse when he was seen at the infirmary-blanched, sweating, and pulseless, with shallow sighing respirations and a subnormal temperature. He himself was unable to give any account of his illness, but his mother, who was with him, stated that he had been under treatment at the Royal Infirmary some two years previously for vomiting of blood. She also said that there had been no history of any digestive disturbance at all, at that time or since. She was very emphatic on this point, as stress had been laid on this absence of gastro-intestinal disorder at the time of his first bleeding. From her account he had lived an exceptionally steady healthy life, and had never had any illnesses at all with the exception of these attacks of hæmatemesis.

The patient continued to bring up blood in the accident room, and was sent up to the ward at once, any examination being out of the question. He was transfused as soon as he reached the ward, and revived sufficiently to enable the pulsations in the radial artery to be felt. 'This improvement was immediately followed by a severe attack of bleeding, necessitating further transfusion. He then definitely im proved, and complained of severe epigastric pain, more or less diffused over the whole of this region. He was given some morphia and went to sleep. He remained in this condition for some eight hours, when he suddenly became restless, and the shallow respirations returned. The pulse at the wrist failed almost immediately, and the patient died a few minutes after the onset of these symptoms. There was no appearance of any bloor externally, and it was supposed that he had had a severe internal bleeding.

A post-mortem examination was performed on the day after death by Dr. W. B. Anderton.

Necropsy.-The body was that of a muscular, well-developed young man, the skin and mucous membranes showing marked pallor. Fat was present in the subcutaneous tissues in fair

enlargement of the superficial lymph glands. 14t oz. It was firm and conical in shape. The myocardium was pale 14t oz. It was firm and conical in shape. The myocardium was pale and of good consistence. There were numerous patches of subendocardial hæmorrhages in the left ventricle, and especially over its septal
wall. The walls of the left ventriele were thickened. There was no wall. The walls of the left ventricle were thickened. There was no
dilatation. The right and left auricles and the right ventricle were
normal. The auriculo-ventricular, aortic, and pulmonary valves were normal. The auriculo-ventricular, aortic, and pulmonary

normal. The aorta and coronary arteries were healthy.
The right and left pleuræ were normal. The right lung weighed 21 $\frac{1}{2}$ oz., collapsed well, and showed moderate pigmentation. It was spongy and crepitant throughout, moderately congested, and exuded a small quantity of frothy serous fluid on compression. The left lung weighed $17 \mathrm{oz}$, and presented the same appearances. The air passages were normal.

Alimentary canal. There were no signs of varices or ulceration in the walls of these viscera. A fairly large amount of blood occupied the lumen of the large intestine and of the lower half of the small intestine. There was no undue distension of the bowels and no sign of blood in the stomach contents. The pancreas was normal. The omentum showed the presence of fat

toneum was dry but otberwise normal.

The spleen was much enlarged, firm, deep purple in colour, and dry. Its upper polme was finty adierent to the There was no iodine reaction.

The thymus gland was absent. The adrenals were normal.

The right kidney was enlarged, weighing $6 \frac{1}{2}$ oz. It was of flabby consistence, and the capsule was fairly adherent. The surface was smooth except along the convex border, where it was distinctly grannlar. The except along the convex border, where it was distinctly grannlar. The ing. The medulla was a deep red. There was no iodine reaction. The urinary passages, genital glands, genital ducts, and external genitals urinary passa

The liver weighed $84 \mathrm{oz}$. It was enlarged as a whole, much alterert in contour and distorted in shape. The consistence generally was very firm. The right lobe was almost globular. The left lobe was much thicke and more rounded than normal, and presented a distinct large boss on its under surface. On section this lobe presented several large, dry yellow, cheesy areas, some of the area of a shilling, and well encapsuled in a thick grey fibrous capsule. The capsules of these gummata fused
with each other and sent forth long and broad strands, dividing the with each other and sent forth long and broad strands, dividing the
substance of the liver up into large areas of liver tissue of a homosubstance of the liver up into large areas of liver tissue of a homogeneous. pale brownish-yellow colour. The anterior part of this lobe was, however, of a still paler colour, presenting a fine mottling on section and being extremely tough. No large gummata were found in the right lobe, which was of a slightly mottled brownish-yellow colour. In its substance could be seen thick strands of fibrous tissue, but these were not as well-defined as those in the left lobe. The portion of the liver that united the two lobes appeared to be fairly normal. There was no iodine reaction. There were much thickening and opacity of the fibrous capsule, with almost inseparable adhesions to the diaphragm. right lobe.

Microscopical appearances.-Liver : Gumma of typical appearance and surrounded by a thick fibrous capsule. The liver tissue in the neighbourhood showed very marked cirrhosis of a very cellular nature and of pericellular distribution (infiltration of the lobules) and disorganisation of the lobules. The arterioles showed much thickening of their walls. Heart : Fine fatty change was abundant in some of the fibres. There was no overgrowth of the connective tissue. Kidneys : Numerous patshes, both superficial and deep, of cellular necrosis. - The renal parenchyma was atrophied. The glomeruli were normal. -

The above is an example of an important group of cases of hepatic syphilis, where the disease resembles ordinary cirrhosis of the liver. The symptoms are usually those of pain in the right hypochondrium, with more or less gastric disturbances, occasional hrematemesis, and ascites. Jaundice is rare in these cases of hepatic cirrhosis, and according to Hale White so also is ascites. On examination of the abdomen the liver and spleen are found to be enlarged and firm. Pain generally is a prominent symptom, owing to the perihepatitis and perisplenitis, and although in the case recorded above there appears to have been a remarkable absence of this symptom, yet from the appearance post mortem of the liver and spleen, which were unduly adherent to the diaphragm, some pain almost certainly must have been present at one time or another.

The diagnosis of these cases rests on the preponderance of syphilis over alcohol in the history, and the relief of symptoms by antisyphilitic treatment. Rolleston has pointed out that the routine treatment of ordinary alcoholic cirrhosis consists of potassium iodide, and that cases recorded of cure in this disease are, in all probability, cases of syphilis of the liver.

Two further points of interest in the above case are, 
tirstly, the absence of any blood in the stomach contents any upper parts of the small intestine, and the absence of and bleeding point to be made out post mortem. Death in this case was certiainly due to acute cerebral anæmia, and it is probable that the patient made some sudden movement or exerted himself in some way so as to cause the acute symptoms that immediately preceded death without there being any fresh bleeding. The absence of any apparent breach in the gastric mucosa or enlarged cesophageal veins is most likely due to the collapse that must have occurred in any such veins that may have existed; it is a matter of common knowledge that it is often exceedingly difficult to demonstrate post mortem cesophageal varices in subjects that have died from sudden and profuse hæmatemesis owing to the empty and collapsed condition.

I am indebted to Dr. R. T. Williamson for permission to record this case and to Dr. Anderton for bis notes on the post-mortem examination.

Manchester.

\section{CASE OF SUBCORTICAL CEREBRAL TUMOUR,}

TUBERCULOUS IN NATURE, REMOVED BY OPERATION ; RECOVERY.

Bx GEORGE HALT, M.D. LoND., M.R.C.P. LoND., ASSISTANT PHYSICIAN, ROYAL VICTORIA INFIRMARY, NEWCASTLE-ON-TYNE; AND

H. BRUNTON ANGUS, M.S. Durh., F.R.C.S. Eng., SURGEON, ROYAI VICTORIA INFIRMARY.

THE case, the notes of which are published below, seems to us to possess features warranting its publication. It illustrates the difficulty of making a complete topical diagnosis of a cerebral tumour; the difficulty of deciding whether to make an attempt to find the tumour by operation, or whether to do merely a decompressive operation; and it shows the final removal of an encapsuled tumour as the result of a happy accident.

The patient was a miner with a negative history of specific disease, and with a general good history save for an attack of pneumonia some years before. The family history was negative. Until admission he had been engaged in active work as a miner. In June, 1911, he was admitted to the Royal Victoria Infirmary, Newcastle-on-Tyne, complaining of intense frontal headache on the left side, and also of two or three attacks which he called "fits," in which he did not lose consciousness, but noted some "tightening and jerking" in his right leg, where there was also at these times a sensation of "tingling." Observation for several weeks produced no result. He had no attacks and no physical signs. Other sources of headache, nasal or ophthalmic, were excluded. His optic discs were normal.

In October, 1911, the patient was re-admitted with a more definite history of fits. His headache persisted as before, but was less intense. The fits he now described as follows: The tingling sensation began about his right ankle and calf muscles, followed by a tightening and then a jerking in the leg. The same condition then appeared in the right arm and the right face, so that he could not speak. After an interval of doubtful length he said the attack gradually passed off and left him with some little temporary weakness of the right arm and leg. He said that on two occasions after the movements had reached his arm and face he lost consciousness, the whole attack lasting 10 or 15 minutes. Observations during his period of unconsciousness were only made by friends and are not helpful. Again on examination there were no symptoms which pointed to gross disease. There was no lack of power on the right side, and the reflexes were normal in type and degree. There was not sufficient evidence to show the cause of the Jacksonian attacks, and he was again discharged. Iodide treatment had been well pushed during the four months previous, up to 150 grains daily.

The patient was not seen again until April, 1912, when his medical man sent him up again for examination. The man said that he had had some of the smaller attacks and two of the larger in which he lost consciousness. He had had no vomiting whatsoever throughout his illness. We found now that there was some slight weakness in the right arm and leg, but not sufficient to cause any characteristic gait or posture. The reflexes on the right side were slightly increased, and there occasionally was an extensor plantar response on the right side. Sensation to light touches was retained over the right arm and leg, but over the latter did not appear so keen as on the left side. Topognosis was not so accurate about the right leg as on the left side, but the results were variable and irregular. Stereognosis about the hand and leg retained. On ophthalmoscopic examination we found distinct signs of neuritis, greater in the left eye where the edge of the disc was invisible as such, the physiological cup filled in, the vessels buried here and there and dipping abruptly from the position of the disc on to the retina. The extent of the swelling above the retina was $2 \mathrm{D}$. A similar condition, but to a less degree, was present in the right eye. The fields of vision by the perimeter were practically normal. He had noticed that on standing up suddenly his left eye seemed to go blind for some few seconds.

Inasmuch as well-pushed antispecific treatment had failed it was decided to trephine. A diagnosis of subcortical tumour on the left side beneath the sensori-motor area was made. It was decided to trephine over that area, partly to "decompress," but keeping in mind the possibility of a tumour which might be removable. The moderate degree of accuracy in the localisation compelled us to take this course,

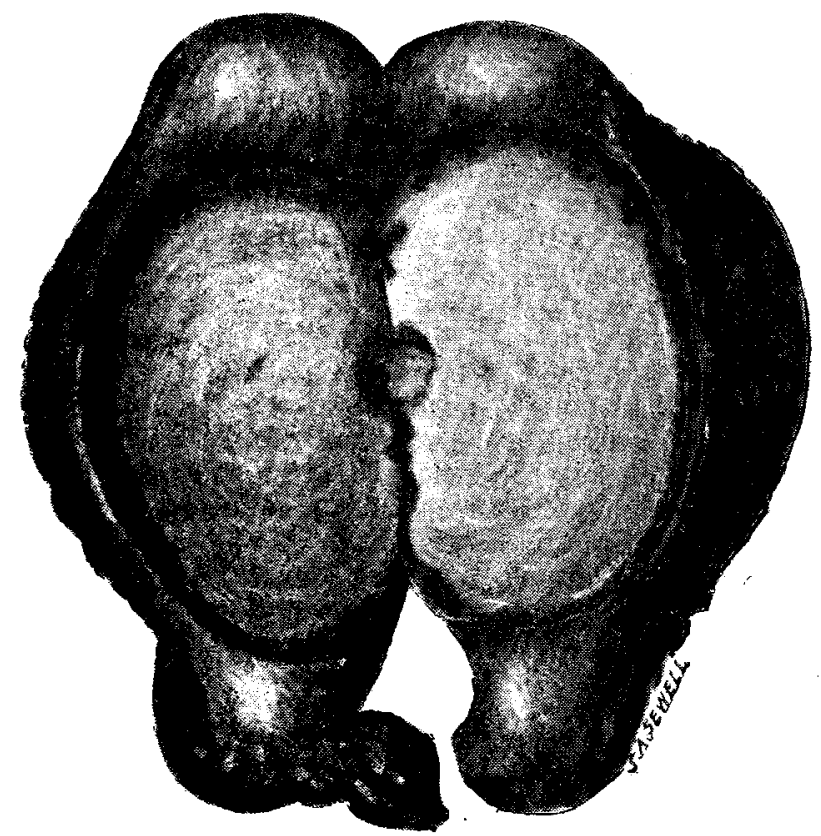

From a water-colour sketch of the specimen. (Natural size.)

rather than do a decompressive operation in a "silent" area, in spite of the risks of resultant hemiplegia and aphasia (see later), all of which were explained to the patient.

Operation.-April 19th, 1912 : A flap of scalp was torned down, and a large portion of bone was removed over the motor area. April 26th: The second stage was undertaken and the dura was incised, the brain substance bulging to a marked degree. There was nothing visible on the surface and the cortex was not incised. The exact field of the operation was mappecl out by electrical stimulation of the cortex. In the course of the operation the superior longitudinal sinus was accidentally wounded, and the copious bleeding could only be arrested by gauze packing. Immediately after the operation the patient became completely paralysed in the right arm, leg, and face, with complete articulatory loss of speech.

May 1st: An attempt was made under anæsthesia to remove the gauze packing, but as the bleeding continued the wound was again plugged. May 8th: The patient was again anæsthetised, and the gauze packing was removed on this occasion without bleeding. The brain substance was protruding and lacerated on the surface. Appearing below the lacerated edges was a white substance which was found to be free ; it was lifted out and found to be an encapsuled tumour. (See fioure.) The wound was closed as much as possible and left to heal, which it did gradually with loss of some brain substance.

The subsequent history of the patient from a surgical point of view was uneventful. His hemiplegia and speech difficulty rapidly showed some improvement, the latter being complete. 'The weakness of the arm and leg greatly disappeared, and when.discharged the patient could walk perfectly well, and also carry out all ordinary movements with the right hand and arm, but with less power than on the left side. He complained of difficulty in appreciating 